\title{
Relaxed Skolam Mean Labeling of 6 - Star Graphs with Partition 3, 3
}

\author{
D.S.T. Ramesh, D. Angel Jovanna
}

Abstract: Existence Relaxed skolam mean labeling for a 6 star graph $G=K_{1, a} \cup K_{1, a} \cup K_{1, a} \cup K_{1, \beta} \cup K_{1, \beta} \cup K_{1, \beta_{3}} \quad$ with partition 3,3 with a certain condition is the core topic of the following article. Trial and error method is used to find the existence of the relaxed skolam mean labeling of 6 - star graph with partition 3, 3 holding a specific condition.

Keywords: Star Graphs, Union of Star Graph, Labeling, Skolem Mean Labeling, Relaxed Skolam Mean Graph.

\section{INTRODUCTION}

The concept of labeling in Graphs plays a vital and undeniable role in the field of planning and networking. Some of the most import labeling functions which are discovered far more earlier and famous were graceful labeling, prime labeling, cordial labeling, mean labeling etc.. In this article we discuss a type of labeling namely Relaxed Skolam Mean Labeling which is extracted from Skolam Mean Labeling of Graphs introduced by V. Balaji et.al.[5] in the year 2010 which in turn is derived from the mean labeling of Graphs .

\section{PRELIMINARIES}

Definition 2.1 [5]: A graph $G=(V, E)$ with p vertices and $\mathrm{q}$ edges is said to be a relaxed skolam mean graph if there exists a function $f: V \rightarrow\{1,2,3, \ldots, p+1=|V|+1\}$ such that the induced edge map $f^{*}: E \rightarrow\{2,3, \ldots, p=|V|+1\}$ given by

Manuscript received on November 29, 2021.

Revised Manuscript received on December 01, 2021.

Manuscript published on December 30, 2021.

* Correspondence Author

Dr. D.S.T.Ramesh*, Associate Professor, Department of Mathematics, Nazareth Margoschis College, Pillayanmanai, Tuticorin, Affiliated to Manonmaniam Sundaranar University, Abishekapatti, Tirunelveli - 627012, India. Email: rameshdstr@gmail.com

D. Angel Jovanna, Research Scholar, Department of Mathematics, Nazareth Margoschis College, Pillayanmanai, Tuticorin, Affiliated to Manonmaniam Sundaranar University, Abishekapatti, Tirunelveli - 627012, India. Email: angeljovanna91@gmail.com

(C) The Authors. Published by Blue Eyes Intelligence Engineering and Sciences Publication (BEIESP). This is an open access article under the CC BY-NC-ND license (http://creativecommons.org/licenses/by-nc-nd/4.0/)

$$
f *(e=u v)=\left\{\begin{array}{lc}
\frac{f(u)+f(v)}{2} & \text { if }(f(u)+f(v)) \text { is even } \\
\frac{f(u)+f(v)+1}{2} & \text { if }(f(u)+f(v)+1) \text { is even }
\end{array}\right.
$$

The resulting distinct edge labels are from the set $\{2,3, \ldots, p+1=|\mathrm{V}|+1\}$

Note: There are $\mathrm{p}$ vertices and available vertex labels are $\mathrm{p}+$ 1 and hence one number from the set $\{1,2,3, \ldots, \mathrm{p}+1=|\mathrm{V}|+1\}$ is not used and we call that number as the relaxed label. When the relaxed label is $p+1$, the relaxed mean labeling becomes a skolam mean labeling.

Result: The three star graph $\mathrm{K}_{1, \mathrm{a}} \cup \mathrm{K}_{1, \mathrm{~b}} \cup \mathrm{K}_{1, \mathrm{c}}$ satisfies relaxed skolam mean labeling if $\mathrm{a}+\mathrm{b} \leq \mathrm{c} \leq \mathrm{a}+\mathrm{b}+\mathrm{c}$.

\section{MAIN RESULT}

Theorem: $\quad$ The 6 - $\quad$ star graph $\mathrm{G}=\mathrm{K}_{1, \alpha_{1}} \cup \mathrm{K}_{1, \alpha_{2}} \cup \mathrm{K}_{1, \alpha_{3}} \cup \mathrm{K}_{1, \beta_{1}} \cup \mathrm{K}_{1, \beta_{2}} \cup \mathrm{K}_{1, \beta_{3}}$ where $\alpha_{1} \leq \alpha_{2} \leq \alpha_{3}$ and $\beta_{1} \leq \beta_{2} \leq \beta_{3} \quad$ is a relaxed skolam mean graph if $\beta_{1}+\beta_{2}+\beta_{3}-\alpha_{1}-\alpha_{2}-\alpha_{3}=7$.

Proof: Let $\sigma_{1}=\alpha_{1} ; \sigma_{2}=\alpha_{1}+\alpha_{2} ; \sigma_{3}=\alpha_{1}+\alpha_{2}+\alpha_{3}$ and $\delta_{1}=\beta_{1} ; \delta_{2}=\beta_{1}+\beta_{2} ; \delta_{3}=\beta_{1}+\beta_{2}+\beta_{2}+\beta_{3}$.

Consider the 6 - star graph $\mathrm{G}=\mathrm{K}_{1, \alpha} \cup \mathrm{K}_{1, \alpha} \cup \mathrm{K}_{1, \alpha} \cup \mathrm{K}_{1, \beta_{1}} \cup \mathrm{K}_{1, \beta_{2}} \cup \mathrm{K}_{1, \beta_{3}}$.

The condition $\beta_{1}+\beta_{2}+\beta_{3}-\alpha_{1}-\alpha_{2}-\alpha_{3}=7$ gives rise to the case $\delta_{3}=\sigma_{3}+7$ In this case we will establish that the graph $\mathrm{G}$ is relaxed skolam mean.

Let the set of vertices of $G$ be $V=V_{1} \cup V_{2} \cup V_{3} \cup V_{4} \cup V_{5} \cup V_{6}$ where

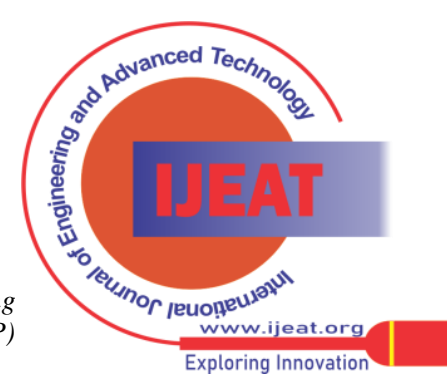


Relaxed Skolam Mean Labeling of 6 - Star Graphs with Partition 3, 3

$\mathrm{V}_{\mathrm{k}}=\left\{\mathrm{v}_{\mathrm{k}, \mathrm{i}}: 0 \leq \mathrm{i} \leq \alpha_{\mathrm{k}}\right\} ; 1 \leq \mathrm{k} \leq 3$ and

$\mathrm{V}_{4}=\left\{\mathrm{v}_{4, \mathrm{i}}: 0 \leq \mathrm{i} \leq \beta_{1}\right\} ; \mathrm{V}_{5}=\left\{\mathrm{v}_{5, \mathrm{i}}: 0 \leq \mathrm{i} \leq \beta_{2}\right\} ; \mathrm{V}_{6}=\left\{\mathrm{v}_{6, \mathrm{i}}: 0 \leq \mathrm{i} \leq \beta_{3}\right\}$. Let the edge set of $\mathrm{G}$ be $\mathrm{E}=\bigcup_{\mathrm{k}=1}^{3}\left\{\mathrm{v}_{\mathrm{k}, 0} \mathrm{v}_{\mathrm{k}, \mathrm{i}}: 1 \leq \mathrm{i} \leq \alpha_{\mathrm{k}}\right\} \cup \underset{\mathrm{k}=4}{\bigcup_{\mathrm{W}}}\left\{\mathrm{v}_{\mathrm{k}, 0} \mathrm{v}_{\mathrm{k}, \mathrm{i}}: 1 \leq \mathrm{i} \leq \beta_{\mathrm{k}-3}\right\}$.

Case: Let $\delta_{3}=\sigma_{3}+7$

G has $\sigma_{3}+\delta_{2}+6=2 \sigma_{3}+13$ vertices and

$\sigma_{3}+\delta_{2}=2 \sigma_{3}+7$ edges.

We define the relaxed skolam vertex function

$\mathrm{f}: \mathrm{V} \rightarrow\left\{1,2, \ldots, \mathrm{p}+1=\sigma_{3}+\delta_{2}+6+1=2 \sigma_{3}+14\right\}$

as follows:

$\mathrm{f}\left(\mathrm{v}_{1,0}\right)=1 ; \quad \mathrm{f}\left(\mathrm{v}_{2,0}\right)=3 ; \mathrm{f}\left(\mathrm{v}_{3,0}\right)=5 ;$

$\mathrm{f}\left(\mathrm{v}_{4,0}\right)=\sigma_{3}+\delta_{3}+5=2 \sigma_{3}+9$

$f\left(v_{5,0}\right)=\sigma_{3}+\delta_{3}+6=2 \sigma_{3}+11$

$\mathrm{f}\left(\mathrm{v}_{6,0}\right)=\sigma_{3}+\delta_{3}+6=2 \sigma_{3}+13$

$\mathrm{f}\left(\mathrm{v}_{1, \kappa}\right)=2 \kappa+5 \quad 1 \leq \kappa \leq \alpha_{1}$

$f\left(v_{2, \kappa}\right)=2 \sigma_{1}+2 \kappa+5 \quad 1 \leq \kappa \leq \alpha_{2}$

$f\left(v_{3, \kappa}\right)=2 \sigma_{2}+2 \kappa+5 \quad 1 \leq \kappa \leq \alpha_{3}$

$\mathrm{f}\left(\mathrm{v}_{4, \kappa}\right)=2 \kappa \quad 1 \leq \kappa \leq \beta_{1}$

$\mathrm{f}\left(\mathrm{v}_{5, \kappa}\right)=2 \delta_{1}+2 \kappa \quad 1 \leq \kappa \leq \beta_{2}$

$f\left(v_{6, \kappa}\right)=2 \delta_{2}+2 \kappa \quad 1 \leq \kappa \leq \beta_{3}$

Here the relaxed label is $2 \sigma_{3}+6$

The edge labels are given as follows:

The edge labels of $v_{1,0} v_{1, \kappa}$ is $\kappa+3$ for $1 \leq \kappa \leq \alpha_{1}$ $\left(2,3, \ldots, \alpha_{1}+1=\sigma_{1}+1\right), v_{2,0} v_{2, j}$ is $\sigma_{1}+\kappa+4$ for $1 \leq \kappa \leq \alpha_{2} \quad\left(\sigma_{1}+5, \sigma_{1}+6, \ldots, \sigma_{1}+\alpha_{2}+4=\sigma_{2}+4\right)$, $\mathrm{v}_{3,0} \mathrm{v}_{3, \mathrm{j}} \quad$ is $\quad \sigma_{2}+\kappa+5$ for $1 \leq \kappa \leq \alpha_{3}$ $\left(\sigma_{2}+6, \sigma_{2}+7, \ldots, \sigma_{2}+\alpha_{2}+5=\sigma_{3}+5\right), v_{4,0} v_{4, j}$ is $\sigma_{3}+\kappa+5$ for $1 \leq \kappa \leq \beta_{1}\left(\sigma_{3}+6, \sigma_{3}+7, \ldots, \sigma_{3}+\beta_{1}+5=\sigma_{3}+\delta_{1}+5\right), v_{5,0} v_{5, \kappa}$ is $\quad \sigma_{3}+\delta_{1}+\kappa+6 \quad$ for $\quad 1 \leq \kappa \leq \beta_{2}$ $\left(\sigma_{3}+\delta_{1}+7, \sigma_{3}+\delta_{1}+8, \ldots, \sigma_{3}+\delta_{1}+\left(\beta_{2}\right)+6=\sigma_{3}+\delta_{2}+6\right)$,

Published By:

Blue Eyes Intelligence Engineering and Sciences Publication (BEIESP) (C) Copyright: All rights reserved. $\mathrm{v}_{6,0} \mathrm{v}_{6, \kappa} \quad$ is $\quad \sigma_{3}+\delta_{2}+\kappa+7 \quad$ for $\quad 1 \leq \kappa \leq \beta_{3}$

$\left(\sigma_{3}+\delta_{2}+8, \sigma_{3}+\delta_{2}+9, \ldots, \sigma_{3}+\delta_{2}+\left(\beta_{3}\right)+7=\sigma_{3}+\delta_{3}+7=2 \sigma_{3}+13\right)$

The edge labels are

$2,3, \ldots, \sigma_{1}+1$

$\sigma_{1}+5, \sigma_{1}+6, \ldots, \sigma_{2}+4$

$\sigma_{2}+6, \sigma_{2}+7, \ldots, \sigma_{3}+5$

$\sigma_{3}+6, \sigma_{3}+7, \ldots, \sigma_{3}+\beta_{1}+5=\sigma_{3}+\delta_{1}+5$

$\left.\sigma_{3}+\delta_{1}+7, \sigma_{3}+\delta_{1}+8, \ldots, \sigma_{3}+\delta_{1}+\left(\beta_{2}\right)+6=\sigma_{3}+\delta_{2}+6\right)$

$\left.\sigma_{3}+\delta_{2}+8, \sigma_{3}+\delta_{2}+9, \ldots, \sigma_{3}+\delta_{2}+\left(\beta_{3}\right)+7=\sigma_{3}+\delta_{3}+7=2 \sigma_{3}+13\right)$

The images of the relaxed skolam edge function of the graph $\mathrm{G}$ are distinct. Hence $\mathrm{G}$ is a relaxed skolam mean graph.

Example:
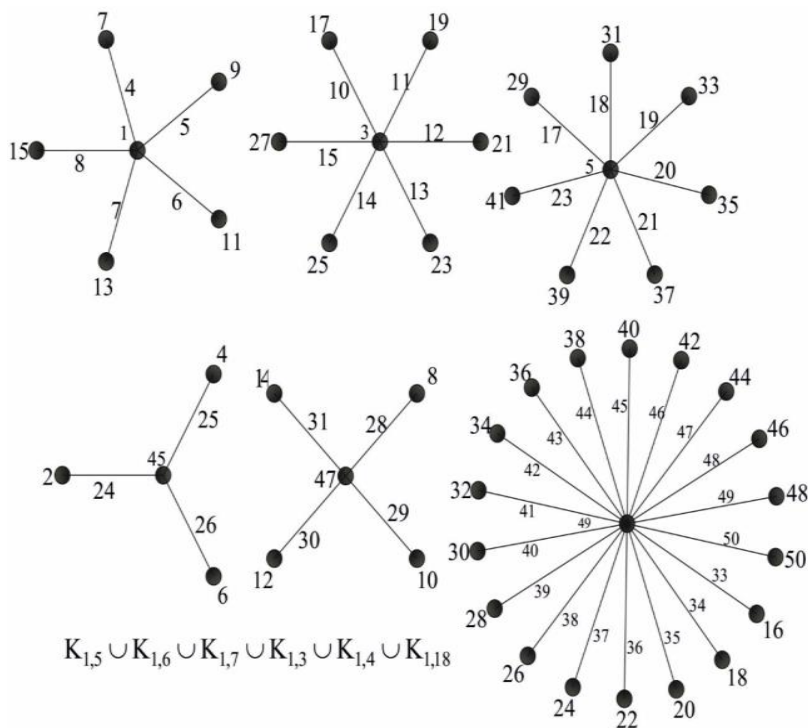

\section{CONCLUSION}

In this research article we concentrated mainly on the existence of relaxed skolam mean labeling of a 6 - star graph $G=K_{1, \alpha} \cup K_{1, \alpha} \cup K_{1, \alpha} \cup K_{1, \beta_{1}} \cup K_{1, \beta_{2}} \cup K_{1, \beta_{3}}$ with the condition $\beta_{1}+\beta_{2}+\beta_{3}-\alpha_{1}-\alpha_{2}-\alpha_{3}=7$. Trial and error method is used to find the existence of the labeling function.

\section{REFERENCES}

1. M. Apostal, "Introduction to Analytic Number Theory", Narosa Publishing House, Second edition, 1991.

2. J. A. Bondy and U. S. R. Murty, "Graph Theory with Applications", Macmillan press, London, 1976

3. J. C. Bermond," Graceful Graphs, Radio Antennae and French Wind Mills", Graph Theory and Combinatories, Pitman, London, 1979, 13 37.

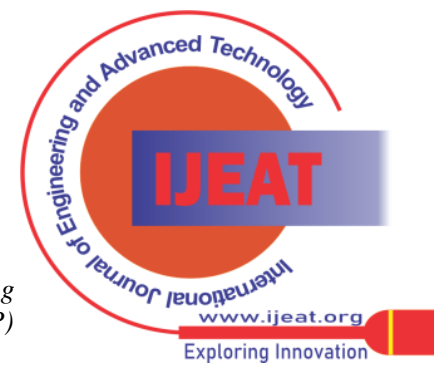


4. V. Balaji, D. S. T. Ramesh and A. Subramanian, "Skolam Mean Labeling", Bulletin of Pure and Applied Sciences, vol. 26E No. 2, 2007, $245-248$.

5. V. Balaji, D. S. T. Ramesh and A. Subramanian, "Relaxed Skolam Mean Labeling", Advances and Applications in Discrete Mathematics, vol. 5(1), January 2010, $11-22$

6. V. Balaji, D. S. T. Ramesh and A. Subramanian, "Some Results On Relaxed Skolam Mean Graphs", Bulletin of Kerala Mathematics Association, vol. 5(2), December 2009, 33 - 44.

7. Abraham k Samuel, J. Vinolin and D.S.T.R. Ramesh, " Relaxed Skolem

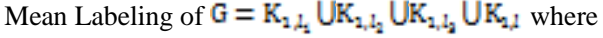

$l_{1} \leq l_{2} \leq l_{3}$ with $\left|l-l_{1}-l_{2}-l_{3}\right|=1$ ", International Journal of Engineering and Advanced Technology (SCOPUS Indexed Journal), Volume 9, Issue 3, 2020, 3743 - 3745, impact factor 0.1, ISSN: 2249 8958.

\section{AUTHORS PROFILE}

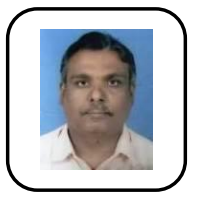

Dr. D.S.T. Ramesh, M.Sc., M.Phil., Ph.D., He is an Associate Professor of Mathematics in Nazareth Margoschis College, Pillayanmanai, Tuticorin, Tamil Nadu. He has 33 years of teaching experience. He guided $8 \mathrm{Ph}$.D."s and $5 \mathrm{M}$. Phil.. His area of specialization is Graph Theory. He published 51 research papers in National and International Journals. He was invited as a resource person for National conferences organized by Sacred Heart College, Tirupattur and Pope's College, Sawyerpuram.

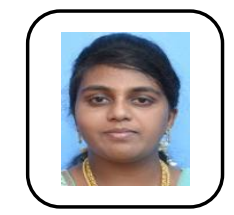

D. Angel Jovanna, Research Scholar of Mathematics in Nazareth Margoschis College, Pillayanmanai, Tuticorin, Tamil Nadu. Attended 3 Internationa conferences, 1 National level Seminar and 1 National level webinar. Presented papers in three International Conferences and published one paper in Turkish Journal of Mathematics.

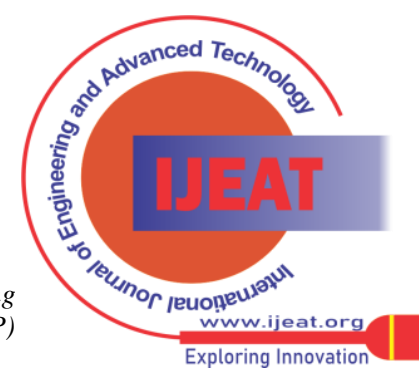

